\title{
Daptomisin ve Bazı Antibiyotiklerin Kan ve Yara Kültürlerinden İzole Edilen Stafılokok Suşlarına Karşı In Vitro Etkinliğinin Araştırılması
}

\author{
Investigation of In Vitro Activity of Daptomycin and \\ Some Antibiotics against Staphylococcus Strains \\ Isolated from Blood and Wound Cultures
}

\begin{abstract}
Özet
Amaç: Bir 13-üyeli aminoasit siklik lipopeptit olan daptomisin özellikle Gram-pozitif bakterilerin tedavisinde kullanılmak üzere geliştirilmiş olan yeni bir antibiyotiktir. Bu çalışmada kan ve yara kültürlerinden izole edilen stafilokok suşlarının daptomisine duyarlıı̆ını ve diğer bazı antibiyotiklere direnç oranlarııı belirlemek amaçlanmıştı.

Gereç ve Yöntemler. Bu çalışmada çeşitli servis ve polikliniklerden gönderilen otuz metisiline dirençli (methicillin-resistant) S. aureus (MRSA), yetmiş metisiline duyarlı (methicillin-susceptible) S. aureus (MSSA), elli metisiline dirençli koagülaz negatif stafilokok (MRKNS) ve elli metisiline duyarlı koagülaz negatif stafilokok (MSKNS) suşunun daptomisin minimal inhibitör konsantrasyonu (MIK), antibiyotik gradient test yöntemiyle araştııımış ve diğer bazı antibiyotik duyarlııkları değerlendirilmiştir.

Bulgular. Daptomisin, vankomisin ve linezolide tüm suşların duyarlı olduğu tespit edilmiştir. MRSA, MSSA ve MSKNS suşları için daptomisin $\mathrm{MiK}_{50} / \mathrm{MiK}_{90}$ değerleri 0,064/0,094 $\mu \mathrm{g} / \mathrm{ml}$, MRKNS suşları için ise $\mathrm{MiK}_{50} / \mathrm{MiK}_{90}$ değerleri 0,094/0,25 $\mu \mathrm{g} / \mathrm{ml}$ olarak bulunmuştur.

Tartışma ve Sonuç: Daptomisin MiK değerlerinin uygulanabilir değerlerde saptanmış olması, kliniklerde glikopeptitlere ve linezolide alternatif olarak kullanılabileceğini düşündürmektedir. Uygun kullanımının sağlanması ile de direnç gelişiminin önlenmesi sağlanabilecektir.

Anahtar Sözcükler. daptomisin; duyarlılık; linezolid; Staphylococcus aureus
\end{abstract}

\section{Abstract}

Aim: Daptomycin is a 13-member amino-acid cyclic lipopeptide and a new antibiotic that has been developed especially for use in the treatment of Gram-positive bacteria. In this study we aimed to determine the level of susceptibility to daptomycin and resistance to some other antibiotics of Staphylococcus strains isolated from blood and wound cultures.

Materials and Methods: In this study, the minimal inhibitory concentration (MIC) for daptomycin of thirty methicillin-resistant $S$. aureus (MRSA), seventy methicillin-susceptible S. aureus (MSSA), fifty methicillin-resistant coagulase-negative staphylococci (MRCNS) and fifty methicillin-susceptible coagulase-negative staphylococci (MSCNS) that were sent from various clinics was evaluated by the methods of antibiotic gradient and other antimicrobial susceptibility testing.

Results: All of the strains were found susceptible to daptomycin, vancomycin, and linezolid. Daptomycin $\mathrm{MIC}_{50} / \mathrm{MIK}_{90}$ values for the MRSA, MSCNS and MSSA strains were found to be $0.064 / 0.094 \mu \mathrm{g} / \mathrm{ml}$ and MIC $_{50} /$ MIK $_{90}$ values for the MRCNS strains $0.094 / 0.25 \mu \mathrm{g} / \mathrm{ml}$.

Discussion and Conclusion: The finding that daptomycin MIC values are in the applicable interval suggests that daptomycin can be used as an alternative to glycopeptides and linezolid in the clinic. Development of resistance is preventable when its appropriate use is ensured.

Keywords: daptomycin; susceptibility; linezolid; Staphylococcus aureus
Mustafa Güzel, Doğan Akdoğan

Sofya Üniversitesi "Sv. Kliment
Ohridski" Biyoloji Fakültesi
Mikrobiyoloji Anabilim Dalı
Sofya/Bulgaristan
29 Mayıs Devlet Hastanesi
Mikrobiyoloji Laboratuvarı, Ankara

Geliş Tarihi /Received : 16.06.2016 Kabul Tarihi /Accepted: 31.07.2016

Sorumlu Yazar/Corresponding Author Dr. Mustafa Güzel

Sofya Üniversitesi "Sv. Klimen Ohridski" Biyoloji Fakültesi Mikrobiyoloji Anabilim Dalı Sofya/Bulgaristan

E-mail: dr.mustafaguzal@hotmail.com 


\section{GíRiş}

Stafilokoklar genellikle deri ve mukozaların normal flora bakterileri olup firsatçı enfeksiyonlarla karşımıza çıkabilmektedir (1). Günümüzde antibiyotik direnç oranlarının yüksek olması nedeniyle yeni antibiyotiklere olan gereksinim de artmaktadır. Tigesiklin, linezolid, kinupristin-dalfopristin gibi antibiyotiklerin yanı sıra daptomisin de Gram-pozitif bakterilerin neden olduğu enfeksiyonların tedavisinde kullanılabilen yeni seçenekler arasında yer almaktadır (2).Daptomisin, Streptomyces roseosporus tarafından doğal olarak üretilen 13 üyeli aminoasit siklik lipopeptittir. Grampozitif bakterilerin duvarındaki lipoteikoik asidin içinde transmembran kanallar oluşturmakta, böylece bakteri membranının sentezini bloke ederek etki göstermektedir (3). Dirençli stafilokok, enterokok ve streptokoklara karşı etkinliği bulunan daptomisinin, ülkemizdeki klinik kullanım endikasyonları diğer ülkeler ile aynı olup, Staphylococcus aureus bakteriyemisi ve $S$. aureus'a bağlı sağ kalp endokarditi ile komplike deri ve yumuşak doku enfeksiyonlarından oluşmaktadır. Bu nedenle de kan kültürü ve yara kültürlerinden izole edilen stafilokokların daptomisin duyarlılıklarının bilinmesi tedavinin planlanması açısından önemlidir (2). Bu çalışmada kan ve yara kültürlerinden izole edilen stafilokok suşlarının daptomisin duyarlılıklarının otomatize sistem ve antibiyotik gradient testi ile araştırılması ve diğer bazı antibiyotiklere direnç oranlarının belirlenmesi amaçlanmıştır. Bu sayede glikopeptitlere ve linezolide alternatif olabilecek bir antibiyotik olan daptomisinin klinisyenler tarafindan kullanımı teşvik edilmiş olacaktır.

\section{GEREÇ VE YÖNTEM}

Düzce Üniversitesi Tip Fakültesi Tibbi Mikrobiyoloji Anabilim Dalına Temmuz 2013-Mayıs 2015 tarihleri arasında, çeşitli kliniklerden gönderilen kan ve yara kültürlerinde üreyen 30 metisiline dirençli (methicillin-resistant) S. aureus (MRSA), 70 metisiline duyarlı (methicillin-susceptible) S. aureus (MSSA), 50 metisiline dirençli koagülaz negatif stafilokok (MRKNS) ve 50 metisiline duyarlı koagülaz negatif stafilokok (MSKNS) olmak üzere toplam 200 suş çalışmaya alınmıştır. Suşların 140’ı (\%70’i) kan, 70’i (\%30’u) ise yara kültürlerinden izole edilmiştir. Steril şartlarda alınıp
BACTEC besiyeri şişelerinde gönderilen kan örnekleri, normal atmosfer koşullarında, $35^{\circ} \mathrm{C}$ 'de BACTEC otomatik kan kültür (Becton Dickinson, $\mathrm{ABD}$ ) cihazında inkübe edilmiştir. Besiyerleri yedi gün süreyle takip edilmiş ve üreme sinyali veren şişelerden, Gram boyama yapılıp, \%5 koyun kanlı (Salubris, Türkiye) agara pasajlanarak $37^{\circ} \mathrm{C}$ 'de 24 saat inkübe edilmiştir. Steril eküvyon çubuklarla alınıp laboratuvara gönderilen yara örnekleri ise \%5 koyun kanlı ve EMB (eosin-methylene blue) agara (Salubris, Türkiye) yayılarak $37^{\circ} \mathrm{C}$ 'de 24 saat inkübe edilmiştir ve Gram boyama işlemi yapılmıştır. Üreyen mikroorganizmaların tanımlanmasında, konvansiyonel yöntemler (besiyerinde koloni morfolojisi, Gram boyanma özellikleri, katalaz testi, tüpte koagülaz testi) ve Phoenix 100 BD Otomatize Sistem (Becton Dickinson Diagnostic Systems, Sparks) kullanılmıştır. Daptomisin ve vankomisin duyarlılığı antibiyotik gradient test (bioMérieux, Fransa) kullanılarak araştırılmış olup, diğer antibiyotiklerin duyarlılıkları disk difüzyon ve/veya otomatize sistemle (Becton Dickinson Diagnostic Systems, Sparks) incelenmiştir (4).

\section{BULGULAR}

Çalışmaya dahil edilen suşların tamamı daptomisin, linezolid ve vankomisine duyarlı olarak tespit edilmiştir. Ayrıca metisiline duyarlı suşlarda moksifloksasin direnci saptanmamış olup, metisiline dirençli suşlarda da moksifloksasine karşı diğer antibiyotiklerden daha düşük oranda direnç olduğu görülmüştür. Stafilokok suşlarının çeşitli antibiyotiklere direnç oranları Tablo 1'de görülmektedir.

Antibiyotik gradient test yöntemiyle belirlenen daptomisin minimal inhibisyon konsantrasyonu (MİK) MRSA suşları için 0,064 $\mu \mathrm{g} / \mathrm{ml}$ ile $0,25 \mu \mathrm{g} / \mathrm{ml}$; MSSA suşları için $0,023 \mu \mathrm{g} / \mathrm{ml}$ ile $0,25 \mu \mathrm{g} / \mathrm{ml}$; MRKNS suşları için $0,032 \mu \mathrm{g} / \mathrm{ml}$ ile $0,125 \mu \mathrm{g} / \mathrm{ml}$; MSKNS suşları için $0,032 \mu \mathrm{g} / \mathrm{ml}$ ile $0,25 \mu \mathrm{g} / \mathrm{ml}$ aralığında saptanmıştır. Ayrıca MRSA, MSSA ve MSKNS suşları için MİK $_{50} /$ MIK $_{90}$ değerleri 0,064/0,094 $\mu \mathrm{g} / \mathrm{ml}$, MRKNS suşları için ise $\mathrm{MIK}_{50} / \mathrm{MIK}_{90}$ değerleri 0,094/0,25 $\mu \mathrm{g} / \mathrm{ml}$ olarak bulunmuştur. Stafilokok suşlarının daptomisin MİK değerlerinin dağılımı Tablo 2'de görülmektedir. 
Tablo1. Stafilokok suşlarının çeşitli antibiyotiklere direnç oranları [n (\%)]

\begin{tabular}{lcccc}
\hline Antibiyotikler & $\begin{array}{c}\text { MRSA } \\
\text { n: 30 }\end{array}$ & $\begin{array}{c}\text { MSSA } \\
\text { n: 70 }\end{array}$ & $\begin{array}{c}\text { MRKNS } \\
\text { n: 50 }\end{array}$ & $\begin{array}{c}\text { MSKNS } \\
\text { n: 50 }\end{array}$ \\
\hline Daptomisin & $0(0)$ & $0(0)$ & $0(0)$ & $0(0)$ \\
Vankomisin & $0(0)$ & $0(0)$ & $0(0)$ & $0(0)$ \\
Linezolid & $0(0)$ & $0(0)$ & $0(0)$ & $0(0)$ \\
Penisilin & $30(100)$ & $66(80)$ & $50(100)$ & $42(84)$ \\
Eritromisin & $16(53)$ & $10(15)$ & $43(86)$ & $22(44)$ \\
Klindamisin & $9(30)$ & $7(10)$ & $40(60)$ & $8(16)$ \\
Siprofloksasin & $10(33)$ & $3(5)$ & $39(78)$ & $6(12)$ \\
Moksifloksasin & $4(13)$ & $0(0)$ & $29(58)$ & $0(0)$ \\
Trimetoprim/sülfametoksazol & $6(20)$ & $3(5)$ & $23(46)$ & $6(12)$ \\
Gentamisin & $7(20)$ & $3(5)$ & $27(54)$ & $0(0)$ \\
Tetrasiklin & $5(17)$ & $15(22)$ & $18(36)$ & $15(30)$ \\
\hline
\end{tabular}

\section{TARTIŞMA}

Stafilokok suşları antibiyotiklere hızlı şekilde direnç geliştirdiklerinden tedavi planlanırken mutlaka antibiyotik duyarlılık testleri yapılmalıdır. 1940 'lı yıllarda penisilin G stafilokok enfeksiyonlarında başarıyla kullanılırken günümüzde yüksek oranda direnç görülmektedir (5). Yine 1951'de tüm S. aureus suşları eritromisine duyarlı iken günümüzde yapılan çeşitli çalışmalarda MRSA suşlarında \% 57-69 oranında; MSSA suşlarında ise \%10-17 oranında eritromisin direnci tespit edilmiştir (6-8). Çalışmamızda da benzer şekilde bu oranlar sırasıyla $\% 53$ ve $\% 15$ olarak bulunmuştur. Yüksek direnç oranı nedeniyle eritromisinin MRSA suşları kaynaklı enfeksiyonların tedavisinde çok etkin olmadığı görülmektedir. Kinolonlar stafilokok enfeksiyonlarında tercih edilebilecek antibiyotik gruplarından olup, özellikle 8-metoksifloro-kinolon olan moksifloksasinin komplike ve komplike olmayan deri ve yumuşak doku enfeksiyonlarına neden olan patojenlere in vitro etkili olduğu bilinmektedir $(9,10)$. Yovel ve ark. tavşanlar üzerinde yaptıkları bir çalışma sonucunda göz cerrahisi sonrası gelişebilecek
S. epidermidis enfeksiyonuna karşı en etkili proflaksinin moksifloksasin ile sağlanabileceğini bildirmişlerdir (11). Yakupoğulları ve ark. moksifloksasin duyarlılığını çeşitli klinik örneklerden izole edilen MRSA suşlarında \%45, MSSA suşlarında ise $\% 74$ oranında saptamışlardır (12). Çalışmamızda MRSA suşlarının \%87'sinin, MSSA suşlarının ise tamamının moksifloksasine duyarlı olduğu görülmüştür. Ancak çalışmamızda MRKNS suşlarının moksifloksasine direnç oranı \%58 olarak tespit edilmiştir. Bu durum özellikle metisiline dirençli suşlarda tedavinin zorluğunu göstermektedir. Antibiyotiklere direnç oranlarındaki bölgesel farklılıkların hastanelerin antibiyotik kullanım politikalarına bağlı olabileceği de bilinmektedir.

Daptomisin, vankomisine duyarlılı̆̆ düşük suşların ortaya çıkmasıyla birlikte kullanımı artan, geniş spektrumlu, siklik lipopeptit yapıda bir antibiyotik olup, S. aureus'un etken olduğu komplike deri ve yumuşak doku enfeksiyonlarında günde $4 \mathrm{mg} / \mathrm{kg}$, infektif endokardit ve sepsiste ise günde $6 \mathrm{mg} / \mathrm{kg}$ dozlarında kullanılmaktadır (13). Daptomisine direnç mekanizmaları henüz tam olarak tanımlanmamış olmakla birlikte, ekspresyonu daptomisine dirençli suşlarda $\mathrm{mfrF}$, yycG, rpoC ve rpoB genlerinde değişiklikler ve dltABCD operonunun aşırı ekspresyonu gösterilmiştir (14). Çeşitli çalışmalarda daptomisin MİK değeri araştırllarak antibiyotiğin etkinliği değerlendirilmektedir. Aktaş ve ark. tamamını daptomisine duyarlı bulduklar1 111 MRSA suşu için $\mathrm{MIK}_{50} / \mathrm{MIK}_{90}$ değerini 0,12/0,5 $\mu \mathrm{g} / \mathrm{ml}$ olarak saptamışlardır (15). Hancı ve ark. MRSA ve MRKNS suşlarının tümü için $\mathrm{MİK}_{50} / \mathrm{MİK}_{90}$ değerini 0,125/0,25 $\mu \mathrm{g} / \mathrm{ml}$ olarak bulmuşlardır (6). Afşar ve ark. MRSA suşları için Mİ $_{50} / \mathrm{MIK}_{90}$ değerini 0,125/0,5 $\mu \mathrm{g} /$ $\mathrm{ml}$ olarak tespit etmişlerdir (16). Ertem ve ark. MRSA suşları için $\mathrm{MIK}_{50} / \mathrm{MIK}_{90}$ değerini 0,064/0,125 $\mu \mathrm{g} / \mathrm{ml}$; MRKNS suşları için $\mathrm{MIK}_{50} / \mathrm{MIK}_{90}$ değerini 0,038/0,38 $\mathrm{mg} / \mathrm{L}$ olarak saptamışlardır (17). Çıkman ve ark., yaptıkları çok merkezli bir çalışmada MRSA suşları için

Tablo 2. Daptomisin MIK Değerlerinin Dağılımı [n(\%)]

\begin{tabular}{lcccccccc}
\hline & \multicolumn{7}{c}{ MİK Değeri $(\boldsymbol{\mu g} / \mathbf{m l})$} \\
\cline { 2 - 9 } Bakteri & $\mathbf{0 , 0 2 3}$ & $\mathbf{0 , 0 3 2}$ & $\mathbf{0 , 0 4 7}$ & $\mathbf{0 , 0 6 4}$ & $\mathbf{0 , 0 9 4}$ & $\mathbf{0 , 1 2 5}$ & $\mathbf{0 , 1 9}$ & $\mathbf{0 , 2 5}$ \\
\hline MRSA & - & - & - & $13(44)$ & $4(13)$ & $2(7)$ & $7(23)$ & $4(13)$ \\
MSSA & $2(3)$ & $7(10)$ & $10(14)$ & $38(55)$ & $8(11)$ & $3(4)$ & - & $2(3)$ \\
MRKNS & $1(2)$ & $3(6)$ & $19(38)$ & $18(36)$ & $7(14)$ & $2(4)$ & - & - \\
MSKNS & - & $10(20)$ & - & $30(60)$ & $7(14)$ & $2(4)$ & - & $1(2)$ \\
\hline
\end{tabular}


MİK $_{50} / \mathrm{MİK}_{90}$ değerini $0,19 / 0,38 \mu \mathrm{g} / \mathrm{ml}$ olarak tespit etmişlerdir (18). Çalışmamızda ise MRSA suşlarının Mİ $_{50} /$ MIKK $_{90}$ değerleri 0,064/0,094 $\mu \mathrm{g} / \mathrm{ml}$, MRKNS suşlarının $\mathrm{MİK}_{50} / \mathrm{MIKK}_{90}$ değerleri 0,094/0,25 $\mu \mathrm{g} / \mathrm{ml}$ olarak bulunmuş olup ülkemizde yapılan diğer çalışmalarla benzer sonuçlar alınmıştır. Şamlıoğlu ve ark. çalışmasında ise MRSA ve MRKNS suşları için $M \dot{I} K_{90}$ değerini $1 \mu \mathrm{g} / \mathrm{ml}$ olarak saptamışlardır (7). Bu durumun çalışmaya dahil ettikleri hastaların tamamının yoğun bakım servisinde tedavi gören hastalar olmasindan kaynaklanabileceği düşünülmüştür. Lee ve ark. 189 MRSA suşu için daptomisin MİK değerini $\geq 0.38$ mg/L olarak bulmuşlardır (19). Sader ve ark. 20052012 yılları arasında Kuzey Amerika, Avrupa, Latin Amerika ve Asya ülkelerinden 164.457 bakteri suşu ile gerçekleştirdikleri çalışmada $S$. aureus için dünya genelinde daptomisin duyarlıllğının benzer düzeyde olduğu bildirilmişlerdir (20). Yine aynı çalışmada MRSA, MSSA ve KNS suşlarının MÍ $_{50} / \mathrm{MIK}_{90}$ değerleri 0,25/0,5 mg/L olarak saptanmıştır. Çalışmamızda karşılaşılan en yüksek MİK değerlerinin 0,25 olması ve ülkemizde yapılan diğer çalışmaların da genel olarak benzer oranlara sahip olması, dünya geneline bakıldığında ülkemizde daptomisin etkinliğinin daha yüksek olduğunu düşündürmektedir.

Çalışmamızda da saptadığımız gibi, özellikle metisiline dirençli stafilokoklar düşünüldüğünde rutin olarak kullanılan birçok antibiyotiğe karşı yüksek bir direnç söz konusudur. Bu nedenle yakın zamanda geliştirilmiş daptomisin, linezolid gibi antibiyotiklerin tedavide glikopeptitlere alternatif olarak kullanılabileceği düşünülmüştür. Daptomisin MİK değerlerinin düşük bulunmuş olması ümit verici olmakla birlikte, kullanılabilir antibiyotik sayısı giderek azaldığından, antibiyotiklerin uygun süre ve yeterli dozda kullanılmasına özen gösterilerek direnç profilinde önemli olumlu gelişmeler elde edilebilir.

\section{TEŞEKKÜR}

$\mathrm{Bu}$ çalışmanın yapılmasında ve incelenen stafilokok suşlarının temininde yardımlarını esirgemeyen Düzce Üniversitesi Tip Fakültesi Tibbi Mikrobiyoloji Anabilim Dalı Başkanı Prof. Dr. İdris Şahin’e teşekkürlerimizi sunarız.

\section{KAYNAKLAR}

1. Winn W Jr, Allen S, Janda W, Koneman E, Procop G, Schreckenberger $\mathrm{P}$ ve ark. Koneman's Color Atlas and Textbook of Diagnostic Microbiology, 6. ed. Baltimore: Lippincott Williams and Wilkins; 2006:623-71.

2. Sümer Ş. Daptomisin; siklik lipopeptid antibiyotiklerin ilk ve tek üyesi, Selçuk Tıp Derg. 2012;28(3):205-8.

3. Özaras R, Tabak F. Daptomisin. Klimik Derg. 2010;23(2):35-8.

4. Performance Standards for Antimicrobial Susceptibility Testing; Twenty-Second Informational Supplement (M100-S22). Wayne, PA: Clinical and Laboratory Standards Institute; 2012.

5. Cengiz AT. Staphylococcus. In: Ustaçelebi Ş (ed.), Temel ve Klinik Mikrobiyoloji. Ankara: Güneş Kitabevi; 1999:339-47.

6. Hancı H, Uyanık MH, Bilici D, Albayrak A, Ayyıldız A. Klinik örneklerden izole edilen metisiline dirençli stafilokok suşlarında daptomisin etkinliğinin araştırılması. ANKEM Derg. 2013;27(2):64-9.

7. Şamlığlu P, Ece G, Atalay S, Köse Ş. Yoğun bakım birimlerinden izole edilen Gram pozitif koklarda daptomisin duyarlılı̆̆1. ANKEM Derg. 2011;25(3):173-7.

8. Çelik C, Bakıcı MZ, Gözel MG, Engin A, Kaya H. Kan akımı enfeksiyonlarından izole edilen Staphylococcus aureus suşlarında antimikrobiyal direnç paterni. Genel Tip Derg. 2013;23(4):109-13.

9. Evirgen Ö. Deri ve yumuşak doku infeksiyonlarında ampirik tedavi. Yoğun Bakım Derg. 2012;10(3):120-7.

10. Azap A, Özkan S, Aygün H, Gül S, Yağcı D, Memikoğlu $\mathrm{O}$ ve ark. Moksifloksasin ve siprofloksasinin Staphylococcus aureus suşlarına karşı in-vitro etkinliği. İnfeksiyon Derg. 2005;19(1):97-100.

11. Yovel OS, Eliahu SB, Kleinmann G. Prevention of Staphylococcus epidermidis endophthalmitis by different moxifloxacin prophylaxis routes. Curr Drug Deliv. 2015; $8: 31$.

12. Yakupoğulları Y, Gündüz A, Özcan M, Doğukan M, Seyrek A, Yılmaz M. Staphylococcus aureus suşlarının siprofloksasin, ofloksasin, levofloksasin ve moksifloksasin duyarlılıkları, Firat Tip Derg. 2006;11(1):45-7.

13. Gould IM, Miro JM, Rybak MJ. Daptomycin: the role of high-dose and combination therapy for Gram-positive infections. Int J of Antimicrob Agents. 2013;42(3):20210 .

14. Sancak B. Staphylococcus aureus ve antibiyotik direnci. Mikrobiyol Bul. 2011;45(3):565-76.

15. Aktaş G, Derbentli Ş. Daptomisinin VRE ve MRSA suşlarına in vitro etkinliği, Mikrobiyol Bul. 2014;48(1):1238.

16. Afşar İ, Güngör S, Şener AG, Demirci M. Daptomisinin kan kültürlerinden izole edilen metisiline dirençli Staph- 
ylococcus aureus suşlarına in vitro etkinliği. Mikrobiyol Bul. 2011;45(4):755-7.

17. Şamlıŏlu P, Ece G, Atalay S, Köse Ş. Yoğun bakım birimlerinden izole edilen Gram pozitif koklarda daptomisin duyarlılı̆̆ı. ANKEM Derg. 2011;25(3):173-7.

18. Çıkman A, Aydın M, Gülhan B, Parlak M, Gültepe B, Kalaycı Y ve ark. Metisiline dirençli Staphylococcus aureus izolatlarının antibiyotik direnci ve azalmış vankomisin duyarlılığının araştırılması: çok merkezli bir çalışma. Mikrobiyol Bul. 2015;49(2):240-8.
19. Lee HY, Chen CL, Liu SY, Yan YS, Chang CJ, Chiu CH. Impact of molecular epidemiology and reduced susceptibility to glycopeptides and daptomycin on outcomes of patients with methicillin-resistant staphylococcus aureus bacteremia. PLoS One. 2015;10(8):e0136171.

20. Sader H S, Farrell DJ,.Flamm RK, Jones RN. Daptomycin activity tested against 164457 bacterial isolates from hospitalised patients: summary of 8 years of a Worldwide Surveillance Programme (2005-2012). Int J Antimicrob Agents. 2014;43(5):465-9. 